\title{
EL TRATAMIENTO DE LOS OLVIDADOS EN EL CINE IRANÍ CONTEMPORÁNEO: MUJER, INFANCIA Y MINORÍAS ÉTNICAS
}

\author{
Zoila Díaz-Maroto Fdez-Checa \\ mariazoila.diazmaroto@urjc.es \\ Universidad Rey Juan Carlos
}

\author{
Elena Carrillo Pascual \\ e.carrillo.pascual@gmail.com \\ Universidad Rey Juan Carlos \\ Belén Puebla Martínez \\ bpuebla@ucm.es \\ Universidad Complutense de Madrid
}

Recibido: 26-02-2014

Aceptado: 20-03-2014

\begin{abstract}
Resumen
El cine iraní, lejos de lo que conocemos como cine euro-norteamericano, se ha ido haciendo un hueco dentro de lo que etiquetamos en occidente como cine periférico. Este cine, aunque desconocido por el público general debido a la escasa repercusión comercial que tiene, se caracteriza principalmente por el trasfondo social que representa y del cual, a su vez, se alimenta. El cine iraní es capaz de esbozar lo que su sociedad simboliza, prestando especial atención a la situación de los individuos más desprotegidos, o lo que es lo mismo, el fiel reflejo de su sociedad: los niños, las mujeres y las minorías culturales. Para ello, y sobre todo para burlar la censura y el control férreo del Estado, los cineastas utilizaron durante décadas a los niños para poder mostrar las difíciles condiciones de vida que sufrían los más desvalidos socialmente. De esta forma, con este artículo pretendemos conocer los cambios que se ha producido en la sociedad iraní a través de las obras de sus principales cineastas, así como los recursos utilizados para criticar la situación de su propio país.
\end{abstract}

Palabras clave: Cine, Irán, mujer, infancia, diversidad cultural, excluidos, exclusión social.

\begin{abstract}
Iranian cinema, far from what we know as Euro-American cinema, has been making its space in what is considered in the West to be peripheral cinema. This cinema, although unknown to the general public due to its limited commercial impact, is mainly characterized by the social background that it represents and from which it draws its inspiration. Iranian cinema outlines what its society symbolizes, paying particular attention to those most vulnerable; in other words, presenting a true reflection of Iranian society through its children, women and cultural minorities. To perform this, and especially to thwart censorship and tight state control, children have been used in films for decades to show the difficult living conditions endured by the most socially disadvantaged. Consequently, this article aims to understand the changes that have occurred in Iranian society through the works of its major filmmakers, as well as the resources used to criticize the situation in Iran.
\end{abstract}

Keywords: Cinema, Iran, women, children, cultural diversity, socially excluded, social exclusion. 


\section{Introducción}

Frente a la hegemonía marcada por el cine euro-norteamericano, el cine iraní se antoja fascinante. Las obras de los diferentes directores se han convertido en un caleidoscopio capaz de representar la identidad cultural iraní a pesar de los cambios en el ámbito político, que se manifiestan de manera continua a través de las crisis y fracturas sociales en el país.

De esta forma, aunque las teorías fílmicas se han centrado en analizar y conocer el cine europeo y norteamericano, debemos tener presente el papel de otros cines periféricos, cada vez con mayor peso en la actual cultura globalizada. En este sentido, el cine iraní cobra doble atención, no solo por la importancia de sus creaciones artísticas sino por el trasfondo social que emana de estas. Como afirma Alberto Elena (Santos, 2012: 17), el cine iraní del siglo XXI "se conforma sobre tendencias centrífugas esencialmente trasnacionales", pero sin romper con sus orígenes que lo unen a su tradición cultural. Es por ello que con el presente artículo pretendemos analizar cómo se han representado los cambios en la sociedad iraní en las últimas décadas. Para ello, nos centraremos especialmente en el uso de la imagen de los niños, un recursos utilizado con frecuencia en este cine para poder atravesar las barreras de la censura política y mostrar así, de manera indirecta, la imagen de los olvidados por estas sociedades: las mujeres, las minorías étnicas y los propios niños. Por tanto, en estas películas, se mostrará de una manera realista los problemas que ocasionan tanto la marginación económica, como social o cultural a estos colectivos desde un enfoque de denuncia social, mostrándonos, en líneas generales, a individuos marginados y discriminados, bien por razones de sexo, por estatus social, por motivos económicos, por discriminación cultural, o por una mezcla de estos elementos.

Aunque se mencionan diferentes largometrajes, los filmes elegidos para ilustrar este artículo están compuestos por tres películas enfocadas al tema de la situación de la mujer: $E l$ círculo (2000), Offside (Fuera de juego, 2004) y Nader y Simin, una separación (2011); otras tres al tema de la situación de los niños: El globo blanco (1995), Niños del paraíso (1997) y El espejo (1997); y dos al tema de las minorías: Las tortugas también vuelan (2004) y Baran (2001). Aunque si bien hay que decir que hay una fina maraña temática que trasciende y las atraviesa de alguna manera a todas ellas, y que a veces una misma película nos podría servir de 
ejemplo para los tres epígrafes desarrollados. Una muestra de ello es Baran, que nos muestra la pobreza, la situación de la mujer así como las minorías culturales en Irán.

También hay que aclarar que, si bien todas las películas que aparecen tratan sobre los temas de exclusión social a los que hacemos referencia, no están todos aquellos filmes que los desarrollan, entre otras cosas -además de razones obvias de espacio- por los escasos ejemplos que llegan a occidente sobre cine iraní, escaso en cuanto a número de obras, y escaso en temática, esencialmente obras protagonizadas por niños ${ }^{1}$. Aún así, como afirma Nader Takmil y Javier Martín (2003) desde occidente lo apreciamos por la imagen que nos presenta de un país que apenas conocemos.

El visionado de las películas se ha llevado a cabo teniendo en cuenta diferentes elementos para poder analizar los personajes de manera global. De tal forma que no solamente se ha analizado al personaje como tal (estudiando sus aspectos físicos, psicológicos y sociales), sino que se ha puesto en relación con el contexto del relato y de su estructura dentro del espacio-tiempo de la narración.

\section{El cine iraní en su contexto sociopolítico contemporáneo (1985 a 2013)}

En Irán, la política ha estado estrechamente vinculada a la cultura y, a su vez, estas dos esferas han condicionado el desarrollo de la cinematografía del país. En líneas generales, hasta los años sesenta se cultivó un cine escapista, compuesto principalmente por melodramas, comedias y por cine de aventuras. Su razón de ser tenía más que ver con la censura que con los gustos del público. (Elena, 1999: 265).

Aunque el cine se impuso como un espectáculo de masas, la aparición una serie de obras de jóvenes cineastas en los primeros años de la década de los setenta, va a permitir hablar de un "nuevo cine" o cine de autor. Esta década fue una época dorada en la literatura iraní, y el cine supuso para muchos intelectuales y escritores un paso hacia adelante. También fueron

\footnotetext{
${ }^{1}$ Según Gönul Dönmez-Colin -Asian Cinema Studies- y Michèle Levieux -Humanitè -(Contenido extra DVD Baran, 2004) al año se ruedan entre sesenta y setenta películas, y solamente cuatro o cinco son sobre niños. Como éstas son las películas que viajan a los festivales, en Occidente se tiene la impresión de que la mayor parte del cine iraní es sobre niños.
} 
fundamentales las influencias de la nouvelle vague francesa y del neorrealismo italiano ${ }^{2}$, que entraron en el país a través de los cine clubes (Hotait, 2006: 80). La primera edición del Festival de Teherán (1972) sirvió de plataforma a este movimiento, que incluía obras como El chaparrón (1972) de Bahrâm Beizâi o El viajero (1974) que fue el debut en el terreno del largometraje de Abbas Kiarostami (Elena, 1999: 265). Este "nuevo cine” iraní surgió a la par que el resto de nuevos cines europeos, árabes y sudamericanos.

Según Layla Hotait (2006: 75), desde la Revolución de 1979 hasta la actualidad, la industria cinematográfica iraní ha atravesado por una serie de fases que coinciden con las etapas por las que ha ido pasando el régimen político. Es decir, la realización y difusión del cine iraní se ha convertido en una especie de pacto implícito de negociación entre los gobiernos y los directores y/o productores cinematográficos, que han intentado crear cine a pesar de las limitaciones.

Siguiendo el esquema que propone Layla Hotait (2006) haremos un breve recorrido del panorama cinematográfico del cine iraní postrevolucionario:

La primera fase o período de la "Primera República", comienza tras la Revolución de 1979 con el regreso a Irán del Ayatolá Ruhollah Jomeini. En esta etapa, la industria cinematográfica sufrió una recesión que se prolongó durante los primeros años del nuevo régimen. Las películas producidas con anterioridad al nuevo régimen tuvieron que ser retocadas para adaptarse a las nuevas exigencias, ya que se reforzó la censura y se pretendió utilizar el cine como arma propagandística. Se produce, por tanto, una vuelta a la tradición; y se diseñó una cinematografía al servicio de la política de islamización (Hotait, 2006: 75). Los directores tuvieron que adaptarse y adaptar su obra a los nuevos tiempos y a las nuevas censuras. La ley islámica prohibía, por ejemplo, tanto en la vida como en la pantalla, abordar abiertamente las relaciones entre hombres y mujeres que no estuviesen casados o emparentados por vínculos de sangre. Así, vemos que en el cine no se puede mostrar ninguna efusión física, excepto hacia los niños o personas del mismo sexo (Thoraval, 1995: 9). También se van a suprimir las secuencias críticas con el matrimonio religioso musulmán y cualquier comentario

\footnotetext{
${ }^{2}$ La influencia del neorrealismo italiano se debió principalmente a la coincidencia temática y el interés por descripción de la realidad social y de los estratos más desfavorecidos de la sociedad. (Santos, 2012: 24).
} 
negativo sobre el sistema político. Tampoco será posible hacer un primer plano de una mujer porque podía interpretarse como una incitación sexual.

A partir de 1983 al cine de propaganda contra el Sha y de exaltación de la Revolución le sucedieron a otros temas y géneros. La guerra contra Iraq (1980-1988), trajo consigo la realización de películas bélicas, muchas veces mera imitación del modelo hollywoodiense. Junto a esta tendencia, el "cine místico" ${ }^{3}$ fue otra de las corrientes que marcaron la producción de esta época (Elena, 1995: 22). No obstante, la película de gran éxito internacional $-E l$ corredor (1985) de Amir Naderi- dio el aviso de que algo estaba cambiando en el cine iraní.

La segunda fase o época de la "reconstrucción" comienza tras el final de la guerra con Iraq, en 1988, y la muerte de Jomeini, un año después. En este momento se va a producir una división entre las facciones más y menos conservadoras: los que apoyaban a Jamenei, líder supremo; frente al presidente Hashemi Rafsanyani (Hotait, 2006: 78). Pero no será hasta el año 1990, cuando el cine iraní despegue de manera internacional, coincidiendo con la gran retrospectiva organizada por el Festival de Pesaro.

De esta manera, salvo algunos cineastas exiliados, todas las grandes figuras del cine de los años setenta van a retomar su carrera: Kiarostami, Naderi, Mehrjui o Beyzai, entre otros. Además, junto a ellos, va a surgir una nueva generación de cineastas en el panorama cinematográfico que secundarán a los directores consagrados en la renovación de la cinematografía (Elena: 1999, 276). En estos años proliferarán las películas construidas sobre la estructura del "mito del niño sabio"4 . Las historias se adaptaron a la estructura del mito y, poco a poco, el protagonismo lo empiezan a acaparar los niños.

La tercera fase se inicia con la elección de Mohammad Jatami en 1997 como presidente, quien realiza una serie de cambios que afectan de nuevo al país, pero también al cine. Aunque Jatami $^{5}$ abogó por una progresiva liberalización de la censura en el ámbito cinematográfico, el

\footnotetext{
${ }^{3}$ Según Alberto Elena (1999: 275), el cine místico es una "variante local del estilo hermético y preocupaciones filosóficas de algunos de los cineastas extranjeros más respetados por el régimen (con Tarkosvsky a la cabeza)".

${ }^{4}$ Según Farshad Zahedi (2012: 134), en El libro de los reyes de Ferdowsi, hay ejemplos que cristalizan la "idea de la unión entre la inocencia infantil y la sabiduría sobrenatural para formar al niño sabio que, tras un viaje iniciático, llega a la madurez y se salva del mundo irracional y de las fuerzas del Mal". El primer niño sabio, en la mitología persa quizás fuera el propio profeta Zaratushtra.

${ }^{5}$ El régimen iraní se caracteriza por la existencia de un entramado de instituciones, unas electivas y otras no, que se limitan entre sí las atribuciones. Además existe un guía supremo por encima de todo que, a su vez, es designado por una Asamblea de Expertos elegida por el pueblo. El choque entre las atribuciones
} 
gobierno bicéfalo de Irán le obligó a enfrentarse con Jamenei, reacio a muchos de los cambios. Jatami dio su apoyo a los sectores más liberales, cosa que no aprobaba Jamenei. Aún así, en esta época se disfrutó de una censura menos estricta, lo que quizá hizo posible la realización de filmes como El sabor de las cerezas, (1997) de Kiarostami, o Dos mujeres, (1998) de Tahmineh Milani (Hotait, 2006: 79).

Además de los maestros del cine iraní, Abbás Kiarostami y Mohsen Makhmalbaf, empezaron a trabajar en sus propio proyectos muchos de los que habían sido sus alumnos o ayudantes. De entre los nombres más destacados ${ }^{6}$ encontramos a Jafar Panahi, discípulo de Kiarostami, que se dio a conocer con El globo blanco (1993), y se confirmó con El espejo (1996), aunque su película más emblemática fue El círculo (2000). Panahi es una de las voces más críticas con el establishment político, tratando temas delicados del régimen y la sociedad iraníes, y pone en evidencia algunas leyes-(Hotait, 2006: 84). Por su parte, Majid Majidi es uno de los especialistas en el cine protagonizado por niños, con largometrajes como El padre (1995), Niños del paraíso (1997) o Baran (2001).

A finales de los años noventa, la fórmula de utilizar niños en el cine parecía estar agotada y, poco a poco, el icono del niño va evolucionar para convertirse en adolescentes y jóvenes y, sobre todo, en mujeres que viven en un trasfondo urbano. La elección de Ahmadineyad (20052013) marca el inicio de la cuarta fase, un período en el que éste endurece las normas que rigen la producción cinematográfica e impone una férrea censura (Hotait, 2006: 79).

Aunque los niños no van a desvanecerse del todo, no serán protagonistas como el pequeño Asmad (Dónde está la casa de mi amigo, 1987) y no se tratarán los universos paralelos e incomunicados de los niños y adultos del cine de Kiarostami, ni siquiera de la rebeldía infantil-juvenil de los personajes de Panahi. Ahora aparecerán tanto adolescentes y jóvenes, como mujeres y hombres, es decir, otras piezas de la sociedad olvidadas por el cine iraní, desde una perspectiva urbana.

de las diversas instituciones constituye un obstáculo para la evolución política del país. (Atalaya Sociopolítica, 2009: 4).

${ }^{6}$ Otros directores que merecen destacarse son, por un lado, Bahman Ghobadi, director iraní de origen kurdo comprometido con su pueblo, que muestra en su obra la situación de los kurdos en Iraq (Las tortugas también vuelan, 2004) o de otros pueblos y minorías. Y por otro, Samira Makhmalbaf, hija del director Mohsen Makhmalbaf, que con solo 18 años realizó su primer filme, La manzana (1998), luego llego La pizarra (2002), etc. (Hotait, 2006: 84). 
Los niños de los años noventa se convertirán en jóvenes que van a desafiar a sus padres, gozando del mismo placer trasgresor del que disfrutaban los niños de las películas de Kiarostami (Zahedi, 2012: 132). Por otro lado, van a copar las pantallas del cine iraní los matrimonios en crisis, muestra de la falta de identidad de una sociedad en plena transformación.

De esta forma, con la llegada de las mujeres protagonistas, se incrementa la crisis de identidad del sujeto masculino en el cine iraní. La consciencia identitaria de los niños y mujeres hará que se rebelen contra el orden masculino y contribuirán de alguna forma a la fragmentación de la figura paterna (Zahedi, 2012: 153). En este sentido, destacan los personajes masculinos del cine de Farhadi $^{7}$ : hombres que aparecen debilitados por las crisis matrimoniales, que al enfrentarse con la nueva consciencia femenina, caen en un precipicio del que no son capaces de salir. El sistema tradicional-paternalista parece desmoronarse y se enfrenta a un caleidoscopio identitario fruto de las nuevas circunstancias sociales de la era de la globalización. Los personajes de Farhadi viven en un espacio en el que parece que no hay rastro de sus tradiciones, ni tampoco de la modernidad. Se encuentran como en el medio de la nada (Zahedi, 2012: 151).

Para acabar, debemos mencionar a la polémica cineasta iraní Tahmineh (Dos mujeres, 1998). Como afirma Janneth Santos (2012: 55), sus obras están llenas de hombres crueles con sus mujeres. Pero a su vez crea una atmósfera feminista en la que intercambia los papeles y las mujeres luchan como hombres, introduciendo así una inversión de los roles. Milani considera que la función del cineasta es ser crítico con el gobierno y con la sociedad; y cree al igual que otros directores, que en Irán hay una crisis de identidad, afirmando que los hombres y las mujeres iraníes llevan una doble vida en público y en privado.

\section{Los personajes más frágiles en el conflicto de la modernidad}

El cine iraní ofrece magníficas películas, no exentas de imágenes de dureza y desamparo que representan situaciones sociales reales, de las que no escapan las mujeres, los niños y las minorías culturales que componen parte de su sociedad.

\footnotetext{
${ }^{7}$ A propósito de Elly (2009), Nader y Simin, una separación (2011), etc.
} 
Como preámbulo, hay que mencionar que la sociedad iraní ha experimentado cambios fundamentales en la composición de su población Si a principios del siglo XX, menos del 20\% de la población vivía en las ciudades, en el año 2007 era más del 70\%. Esto supuso un cambio en la estructura social y productiva, ya que muchos campesinos dejaron sus aldeas para irse a las ciudades en busca de trabajos mejor remunerados. (Elena, 2011: 15). A estas migraciones internas hay que añadirle las migraciones de los países limítrofes, como Afganistán, que han condicionado las relaciones sociales por el hecho de tener que compartir los escasos recursos con los "refugiados".

Otro factor que hay que considerar es que, de los casi 80 millones de habitantes que tiene Irán, tres de ellos son estudiantes universitarios, de los cuales un $62 \%$ son mujeres. A pesar de ello, vamos a ver una constante en toda la filmografía utilizada: la limitación social y cultural a la que las mujeres están sometidas. En estas mujeres va haber una pulsión por escapar, por encontrar un espacio de libertad, y una resistencia a dejarse atrapar por las circunstancias que las anulan. También en estas películas vamos a encontrar niños que se encuentran fuera de su círculo de protección, es decir, el Estado-colegio; familia-casa. Así, ellos tendrán que decidir por su cuenta y afrontar los problemas que les causa las estructuras de una sociedad en crisis, e incluso vivir situaciones límite.

En Irán se da la paradoja de que, si por un lado la desigualdad en la distribución de la renta ha provocado un empobrecimiento de la población; por otro, debido a la mejora del nivel educativo, encontramos un mayor nivel de exigencia por la mejora en los derechos sociales. Encontramos entonces unos personajes que intentan superar la situación crítica en la que viven $\mathrm{y}$, para ello, en su comportamiento aparece una protesta por sus condiciones existenciales, como un deseo de alcanzar el sentido de la vida, más allá de lo cotidiano y en el contexto de las generaciones. Encontramos un análisis más emocional que político, que apuesta y reivindica un modelo de sociedad más justo.

Aún así, aunque no son películas con una intención política explícita, sí aluden de forma permanente al aparato represivo institucional -policía, justicia, autoridad en la escuela- que persiguen a quienes se apartan del orden establecido. Se percibe esa sensación de que los medios de represión son omnipresentes. También van a reflejar una dualidad interior en el ser iraní: de un lado está arraigado en su pasado y, de otro, está en un conflicto con el mundo actual. Por tanto, contraste y conflicto entre tradición y modernidad. 


\subsection{Los personajes femeninos en el cine iraní}

El objetivo de los movimientos feministas es lograr la igualdad social para las mujeres en cuanto a los derechos básicos, o como "afirma Castells desexualizar las diferencias sociales y culturales, rechazando una identidad definida por los hombres para las mujeres y así romper con una 'santidad' en una sociedad patriarcal" (Zahedi: 2010, 164). La era moderna ha permitido abrir un camino para ofrecer una nueva consciencia femenina que les permita recuperar su identidad social. Para Farshad Zahedi (2010: 165), la entrada de la modernidad en Irán es posible que haya servido para la introducción de dichas reflexiones.

Dice Panahi (web Todocine: s.a.) respecto de la mujer: "su libertad es tan limitada que parecen estar en una gran cárcel y no solo una clase determinada de mujeres, sino todas, como si cada mujer pudiese sustituir a otra en un círculo que las hace a todas iguales".

En las películas, los problemas a los que se enfrentan sus protagonistas están muy relacionados con su condición femenina. Esto resulta manifiesto, por una lado, en El círculo ${ }^{8}$ (2004) y en Offside (2004), ambas de Jafar Panahi, donde el hecho de ser mujer priva a las protagonistas de una serie de actividades que son normales para los hombres: ir a un partido de futbol, alojarse en un hotel, viajar, etc. Y por otro, en Nader y Simin una separación (2011) de Asqar Farhadi, por la difícil decisión que toma Simin al marcharse de casa con la consecuencia de perder a su hija. El énfasis de estas limitaciones intenta producir en las mujeres esa sensación de incapacidad por cuidarse por ellas mismas y cuyo objetivo es romper su resistencia al sistema.

\section{Etapa 1979-1989}

Las mujeres han estado en el centro de los conflictos sociales de Irán desde la entrada de la modernidad, así cualquier cambio social importante en Irán ha sido acentuado por los cambios de la definición del papel de la mujer en la sociedad. Tras la Revolución de 1979, con la vuelta hacia las tradiciones religiosas, el gobierno impuso la obligación de llevar hiyab, por lo que la mujer volvió a ser el centro de los conflictos sociales.

\footnotetext{
${ }^{8}$ Panahi va a dar un salto temporal y va convertir a esas niñas que aparecían en El globo blanco o en $E l$ espejo en mujeres, y va a explorar el drama que les toca vivir como adultas, en una sociedad que solo aprecia su condición de reproductoras.
} 
Según Farshad Zahedi (2010: 170), una vez terminada la guerra irano-iraquí, los valores éticos-religiosos de la Revolución y de la época de la guerra (1980-88), fueron sustituidos por unos nuevos valores más materialistas. Con la debilitación de los valores religiosos, la justificación religiosa dejó de ser útil como sistema de control interno y, a la vez el sistema de control externo (la ley) ya no daba resultado puesto que los mismos ejecutores de la ley habían perdido su credibilidad social.

\section{Etapa de Rafsanyani (1989-1997)}

Irán entró en la década de los noventa en plena crisis económica. Con la llegada del gobierno de Hashemi Rafsanyani (1989-1997) se abrió un espacio de debate para definir el aspecto de la mujer y el tema de la familia en la sociedad islámica. En 1992 se creó la Oficina de los Asuntos de la Mujer para detectar problemas y buscar soluciones para mejorar el estatuto de las mujeres. Por otra parte, a diferencia de algunos países de la región, la alfabetización tendió a generalizarse $e^{9}$ en Irán, por lo que el sistema educativo produjo la salida masiva de jóvenes bien formados en busca de trabajo.

Según Zahedi, (2012: 141) a finales de los años 90 el 50\% de los estudiantes de las universidades públicas eran chicas. Esto hizo que las mujeres accedieran a una formación académica que no habían tenido sus madres y abuelas, y poco a poco empezaron a reivindicar sus derechos básicos y a movilizarse contra una desigualdad de género. El resultado fue la vuelta de muchas mujeres profesionales al mundo laboral. Por ejemplo, en la película El círculo, Elham trabaja en un hospital de Teherán. O en Nader y Simin, una separación, Simin es profesional de la enseñanza.

No obstante, la estructura tradicional de la familia está basada en las diferencias de género, a pesar de que en las últimas décadas, la educación superior y el trabajo fuera de casa hayan dado una nueva entidad a la mujer. Esto ha supuesto una dificultad en el camino de la armonización de los papeles tradicionales femeninos con la modernidad. En Irán, el código civil da prioridad al núcleo familiar y a su sostenimiento basado en la autoridad del marido o

\footnotetext{
${ }^{9}$ En la película Niños del paraíso de Majid Majidi, vemos cómo Alí ha recibido una educación que no recibió su padre y queda patente cuando ambos van a los barrios residenciales de Teherán a buscar trabajo. Alí sabe cómo expresarse y relacionarse con las clases sociales superiores.
} 
padre, ${ }^{10}$ como responsables del trabajo fuera de casa. Así en El círculo (2000), Panahi muestra la imagen femenina de la mujer en un entorno urbano, donde la ley dominante es la ley del patriarca, que "no tolera la más mínima insinuación de una mujer independiente, que, por su acceso a su identidad, puede provocar grietas en la estructura del poder y debilitar las bases de un mundo androcéntrico" (Zahedi, 2012: 145).

En la película vemos un mosaico de mujeres a través de varias historias y nos muestra un panorama desolador, con un significado común, las limitaciones que sufre una mujer sola en Irán - "sin un hombre no puedes ir a ningún sitio"- dirá uno de los personajes. En esta película apreciamos la gran desigualdad que supone nacer hombre o mujer ${ }^{11}$. En el caso de Offside (2004), por ejemplo, vemos la exclusión que sufre la mujer iraní, donde además de no poder entrar a un campo de futbol, se le priva del derecho de ir al baño cuando está arrestada por intentar acceder al interior del estadio.

Por otro lado, el papel maternal y los quehaceres domésticos están entre las responsabilidades de la mujer o madre. Al ser considerado el hombre como garante del mantenimiento de la familia, se refuerzan las relaciones tradicionales y patriarcales, que además están respaldadas por la legislación.

También se obstaculiza la participación social de las mujeres, las cuales se encuentran con un vacío legal y se quedan oscilantes entre la modernidad y la tradición. En Nader y Simin, una separación (2011), Simin quiere divorciarse de Nader porque éste no quiere marcharse con ella y su hija del país. Nader argumenta que debe ocuparse de cuidar de su padre, enfermo de Alzheimer. El padre de Nader representa la conciencia tradicional. En Offside, se habla en torno al hecho de que las mujeres iraníes no pueden presenciar partidos de fútbol ${ }^{12}$, uno de los deportes nacionales, porque los hombres llevan pantalones cortos. En este sentido, destaca la escena en la que el padre busca de manera desesperada a su hija entre los hombres que se

\footnotetext{
${ }^{10}$ Según la ley, el padre tiene que mantener a sus hijas hasta que contraigan matrimonio; una vez casadas, la obligación de la manutención pasará a sus maridos.

${ }^{11}$ En la primera escena aparece una madre que ha dado a luz una niña. La abuela dice "menuda desgracia". Es la clave del film: ha nacido un bebé, y a aunque según la ecografía iba a ser niño, la recién nacida es niña. La abuela sabe que su yerno pedirá el divorcio.

${ }^{12}$ Las autoridades justifican también esta prohibición por el uso de un "lenguaje inapropiado" por los aficionados. Las restricciones para que las mujeres no asistan a partidos de fútbol fueron impuestas después de la Revolución Islámica de 1979. (Lloveras, 2014).
} 
dirigen al estadio de Teherán, algo que él considera una blasfemia y que va en contra de las tradiciones impuestas por los "hombres viejos".

La mujer está totalmente desprotegida en el ámbito familiar. En hombre puede divorciarse con facilidad, puede contraer sucesivos matrimonios y tener las concubinas que quiera. Así vemos en El círculo a Monir que ha sido liberada tras una larga condena, descubre que su marido se ha casado con otra mujer. Sin embargo, la mujer, para divorciarse, tiene que probar que su marido es impotente, drogadicto, insolvente o que ha abandonado el hogar más de seis meses. No se consideran motivo de divorcio los malos tratos (Amirian, 2007: 170). El testimonio de la mujer ante un tribunal civil vale la mitad que el del hombre, y ante una testamentaría, la mujer iraní recibirá la mitad de la herencia de sus hermanos varones.

\section{Etapa de Jatami (1997-2005)}

Aunque Jatami (1997-2005) inició cambios, sus políticas reformistas provocaron disputas con los sectores conservadores y la línea dura del gobierno iraní. No obstante, durante su mandato, las mujeres empezaron a tomar protagonismo en el cine. Estas películas -por ejemplo, El círculo de Jafar Panahi (2000)- van a proyectar la defensa de los derechos de la mujer. Algunas activistas iraníes continuaron luchando para obtener más derechos para sí dentro del sistema legal islámico, especialmente en lo relativo a la custodia de los hijos. En Nader y Simin, una separación, Termeh se queda a vivir con su padre tras la separación.

Para Saeed Talajooy (2012: 38-39), en la película El círculo, la vigilancia del régimen actúa como un Gran Hermano sobre la sociedad iraní -especialmente sobre las mujeres- y establece en qué círculos debe configurarse cada elemento de dicha sociedad. Esta amenaza abstracta tiene un aspecto socio-político.

Así vemos que las tres muchachas que acaban de ser puestas en libertad ${ }^{13}$-Nargess, Arezu, y Pari- se mueven asustadas por las calles de Teherán, ${ }^{14}$ huyen de la vigilancia constante, de la dominación masculina. Esta película nos muestra al hombre como un peligro acechante. La presencia de la policía como el elemento represor y ejecutor de la autoridad,

\footnotetext{
${ }^{13}$ No se nos dice en ningún momento cuáles fueron los delitos que llevaron a estas mujeres a la cárcel, quizá, tan solo ser mujer.

${ }^{14}$ Contrasta la imagen de la ciudad de Teherán mostrada en esta película -oscura y asfixiante- con la que aparece en la película Niños del paraíso, cuando Alí y su padre emprenden un viaje a los barrios residenciales de la ciudad en busca de un pluriempleo para sobrevivir. Aparece una ciudad radiante, la Teherán de casas lujosas y hermosos jardines.
} 
resulta angustiosa. Panahi da buena cuenta del impacto que supone el peso de las leyes para los miembros más desfavorecidos de la sociedad.

Imagen 1. Vigilancia constante del régimen, sobre todo de la mujer

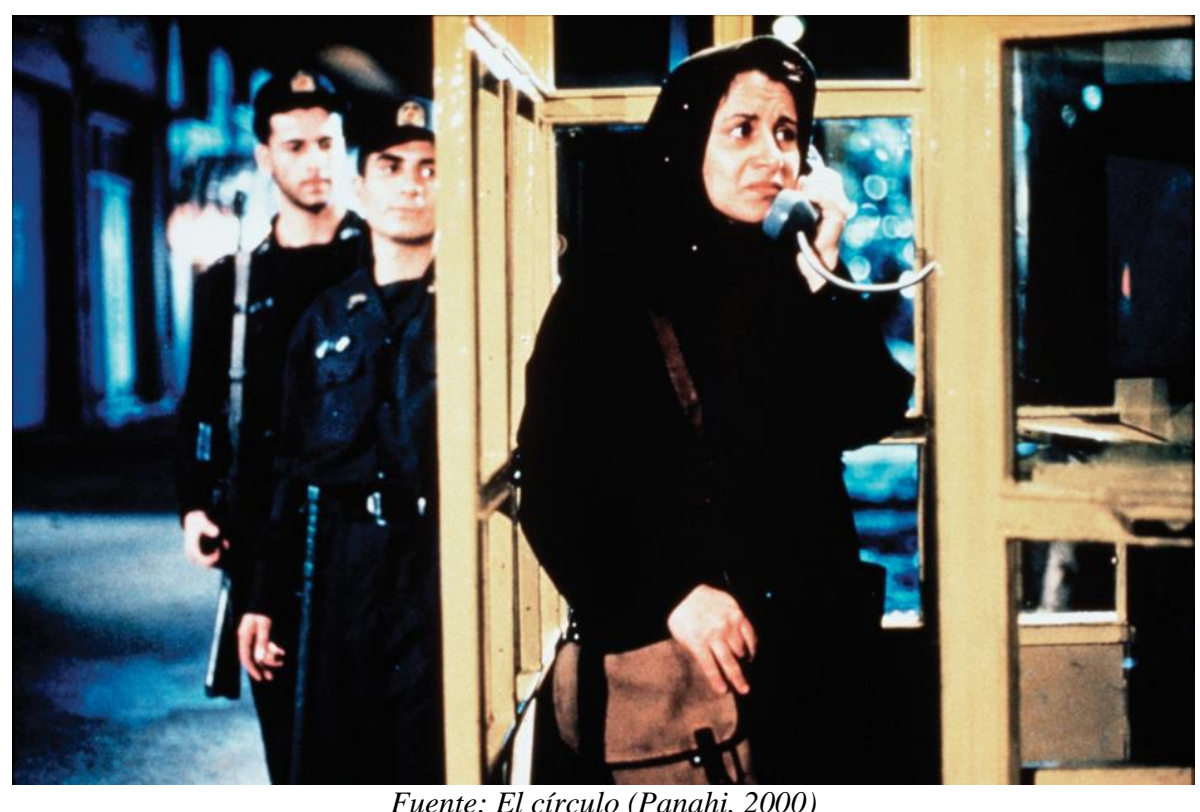

\section{Etapa de Ahmadineyad (2005-2013)}

Cuando Ahmadineyad llegó al poder (2005-2013), intentó poner de manifiesto el efecto dominó que podía desencadenar el movimiento de defensa de la mujer iraní. (Política exterior, 2009: 5). Procedente del ala ultraconservadora del régimen, utilizó un discurso populista y defendió la recuperación de los valores revolucionarios. Pero la difícil situación económica, el desempleo, la represión política y la imposición de las rígidas reglas morales llevaron a muchos jóvenes a la desesperación.

Así, en junio de 2009, muchos iraníes se enfrentaron al gobierno de los clérigos en un conflicto que nada tenía que ver con los problemas religiosos. Salieron a la calle para defender la democracia, al margen de la fe y la sharia. La nación tiene, aunque en proporción indeterminada, un deseo de cambio; y ese deseo está impulsado en buena parte por la mujer iraní (Política exterior, 2009: 5). Por ello, "la protesta contra el régimen clerical es, en buena 
parte, la protesta de las mujeres" (Política exterior, 2009: 5). ${ }^{15}$ Recordemos el caso de Offside, en la que una chica manifiesta su contrariedad no solo al régimen, sino a su propio padre, vistiéndose de hombre para poder entrar en un evento deportivo.

Según Nayereh Tohidi (2009: 43), las mujeres modernas, urbanas y de clase media en Irán, formaron el núcleo de los grupos feministas que se oponían a las leyes y políticas discriminatorias promulgadas por el gobierno islamista desde 1979. Posteriormente, a este núcleo se unieron mujeres activistas islámicas de los sectores más tradicionalistas y conservadores debido a su decepción por la incapacidad del islam para reformarse. A pesar de la naturaleza pacífica del movimiento feminista iraní, muchas activistas han sido víctimas de la represión.

No obstante, pese a la extraordinaria capacidad de resistencia que presentan las mujeres iraníes, su vida no resulta fácil. En Nader y Simin, una separación, el personaje de Simin representa a una mujer liberal, crítica con la realidad que le rodea. Lleva el pelo de color rojo bajo el pañuelo, pantalones vaqueros, fuma a escondidas, etc. Destaca también el contraste entre Simin y Razieh, ${ }^{16}$ mujer cultivada la primera, y casi analfabeta, pobre y que llevan rigurosamente el chador la segunda.

Si por un lado, las mujeres iraníes pueden conducir automóviles, montar negocios y vivir una vida casi normal dentro de la casa; en la vida pública, hay separación de sexos: segregación en autobuses, en playas, en piscinas, en celebraciones. En las películas a través de detalles, podemos palpar lo que es la vida cotidiana de las mujeres: la obligatoriedad del uso del chador por encima del pañuelo y del abrigo hasta los tobillos, la libertad del hombre para tomar varias esposas, la prohibición de viajar solas, la imposibilidad de alojarse en un hotel si van solas, la prohibición de fumar en público, etc. Las mujeres son como cuerpos errantes sobre un trasfondo urbano. En contraste, en El círculo vemos ráfagas de lo que es una ceremonia de boda, la única posibilidad de realización femenina en Irán.

Según Nayereh Tohidi (2009: 45), actualmente, el principal debate entre los defensores de los derechos de la mujer, es “cómo integrar las demandas de la mujer con los objetivos más

\footnotetext{
${ }^{15}$ Razieh, la obstinada y tenaz protagonista de El globo blanco es una sutil representación de la nueva mujer que en algún momento terminará por ser aceptada en la sociedad iraní.

${ }^{16}$ Es la asistenta que contrata Nader para que cuide de su padre. Razieh acusará a Nader de haberla maltratado hasta el punto de provocarle un aborto. Su marido, Houjat, cree que puede sacar dinero con esta acusación.
} 
amplios de reforma y democracia". Esta dicotomía queda muy patente en la película Nader y Simin, una separación, ya que el mecanismo que hace funcionar los conflictos de la película es el dilema moral, la disyuntiva, la elección entre dos posibilidades excluyentes. Los personajes están continuamente debatiéndose entre dos opciones (Rajas, 2012: 212). Será Termeh, la hija Nader y Simin, la que venga a romper esa dualidad de opciones o dilema moral, cuando pide un espacio privado para poder revelar su decisión ante el juez. Su elección -que nunca se sabrámarcará el rumbo de la familia en crisis.

En esta película, se va a producir una convergencia de todas las tendencias del cine iraní de los últimos 30 años. Fahedi va a reunir a todos los personajes que se fueron creando en la fase post-revolucionaria del cine iraní: una "joven sabia" que decide el destino de sus progenitores, hombres y mujeres que buscan su lugar dentro de la sociedad, etc. (Zahedi, 2012: 131). La sucesión de desastres encadenados que provocará la separación de Nader y Simin también revela la lucha de clases en la sociedad iraní y el control de un patriarcado que sigue queriendo silenciar la voluntad de las mujeres.

\subsection{Los personajes infantiles en el cine iraní}

Majidi (2004) dice que en sus películas intenta buscar los sentimientos más puros y las más hermosas virtudes, como la generosidad. Y respecto a esto, no existe un mundo más simple, puro y magnífico que el mundo de los niños. Es por este hecho que lo que se ha venido considerando como el cine iraní de niños nunca ha sido un género totalmente separado del llamado realismo social que nació una década antes de la Revolución.

El realismo social no es un género homogéneo, ya que abarca desde las poéticas películas de Kiarostami con protagonistas de la vida rural, vida de ritmo lento y eventos banales; a algunos ejemplos de películas alegres y entretenidas para y sobre los niños; a oscuras y amargas imágenes de la vida de los niños y adultos iraníes que viven en la extrema pobreza, con duras condiciones en el trabajo (Hosseini-Shakib, 2012: 228).

Según Farshad Zahedi, (2012: 136), la imagen de la infancia va a aparecer en el cine iraní durante la crisis sociopolítica de los años ochenta, debido, por un lado, al endurecimiento de la censura, que hizo que se prohibiera a las mujeres ir sin la vestimenta islámica, el baile, el canto y cualquier demostración sensual explícita; y por otro, a la representación de la imagen 
moderna del "niño sabio", la cual sirvió para realizar una representación de las circunstancias sociales eludiendo la censura. El punto de inflexión de dicha imagen será la película de Abbas Kiarostami ¿Dónde está la casa de mi amigo? (1987).

De esta manera, a partir de los años ochenta hasta finales de los años noventa, los niños ser convierten en el recurso más utilizado por los realizadores para sortear la rígida censura impuesta sobre cuestiones religiosas y políticas. Sirvieron como sustitutos para representar lo que estaba vedado a los adultos, y permitir a los cineastas mostrar temas políticos o sociales, como las críticas sobre las condiciones de vida en Irán. Por ejemplo, Niños del Paraíso (1997) nos muestra la pobreza en la que viven muchos niños y niñas, donde la pérdida de unos zapatos es una tragedia. También plantea el fracaso por salir de la pobreza que experimentan los padres de Alí y Zhara, que es paralelo al fracaso de los niños por conseguir los zapatos para Zhara.

Imagen 2. La pérdida de los zapatos de Zhara supone que ambos hermanos tengan que compartir las zapatillas deportivas para ir a la escuela

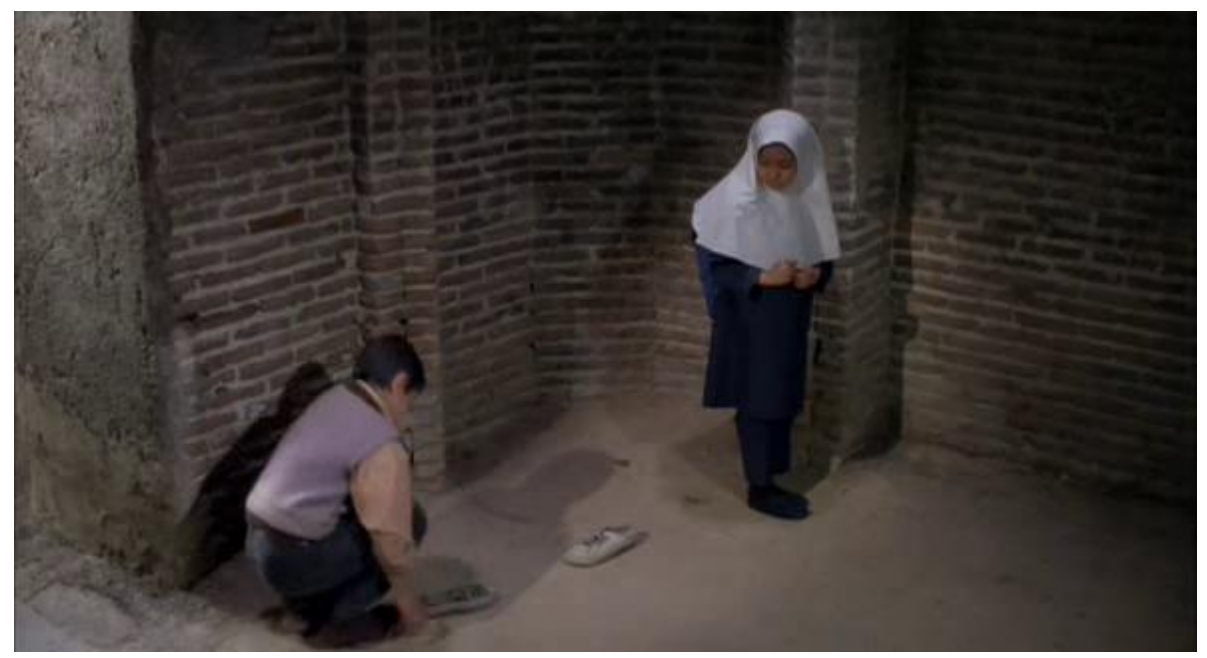

Fuente: Niños del paraíso (Majidi, 1997)

En esta etapa, los niños van a ocupar el centro de la vida social en las obras fílmicas de Kiarostami, Majidi o Panahi -que han tratado el tema de la infancia con frecuencia y profundidad-, y les servirán tanto de modelo a imitar como de referencia simbólica en la construcción de los diferentes universos sociales, culturales y humanos. 
De esta manera, el cine iraní mostrará a la sociedad a través de los ojos de los niños. El niño, aunque ha perdido parte de su inocencia es capaz de seguir soñando y ver esperanza donde solo hay desierto. Su mirada es alegre, desea vivir aún en contra de todo lo que le rodea. La imagen del niño no solo representa, sino que también se convierte en modelo a seguir.

Como dice Francisco García (2012: 157-58), la infancia está presente de una manera constante en el cine iraní, ya sea a través de películas cuyo protagonista central es el niño; ya sea mediante la presencia de los niños de una manera secundaria en el relato cinematográfico. ${ }^{17}$

Sobre los niños también van a gravitar muchas ideas, sentimientos y valores que quiere trasmitir el director. Una de las películas que nos presenta las imágenes más

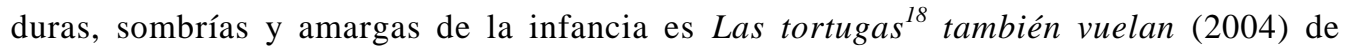
Ghobadi. Es un testimonio real de los despropósitos de la guerra de Irak $^{19}$ en los asentamientos kurdos en la frontera con Irán. Ghobadi reflexiona sobre cómo el conflicto afecta la vida de niños y niñas que han perdido la inocencia y la alegría: ya no juegan, han tenido que crecer a la fuerza y cargan con una historia personal llena de violencia, abusos y dolor.

Ghobadi no muestra en la película la familia tradicional, sino que plasma una sociedad desestructurada como consecuencia de los reveses causados por la guerra, la violencia y la pobreza. En Las tortugas también vuelan, la familia se compone de un hermano y una hermana, junto con un hijo ilegítimo. Los niños de Ghobadi se ven privados del derecho a ser niños y vivir en el mundo de los niños. Ni siquiera tienen tiempo para ir a la escuela porque, como señala "Satélite", "ahora es el tiempo para la guerra, y los niños tienen que tomar las armas y luchar para defender la patria”.

\footnotetext{
${ }^{17}$ Por ejemplo en la película El Círculo (2000) de Jafar Panahi a pesar de que no son protagonistas, son muy importantes tanto la niña recién nacida a la cual no vemos o la niña que es abandonada en la calle por su madre. Ambas marcarán el destino de sus madres (de todas las madres en Irán por el hecho de haber nacido niñas).

${ }^{18}$ La "tortuga" es la mina antipersona.

${ }^{19}$ Un grupo de niños huérfanos con taras reales se ganan la vida en el Kurdistán buscando y vendiendo las minas antipersona a la ONU -de las que han sido víctimas-, o canjeándolas por armas en el mercado negro.
} 
Imagen 3. En la frontera irano-turca, los niños kurdos se dedican a buscar minas anti-persona para venderlas

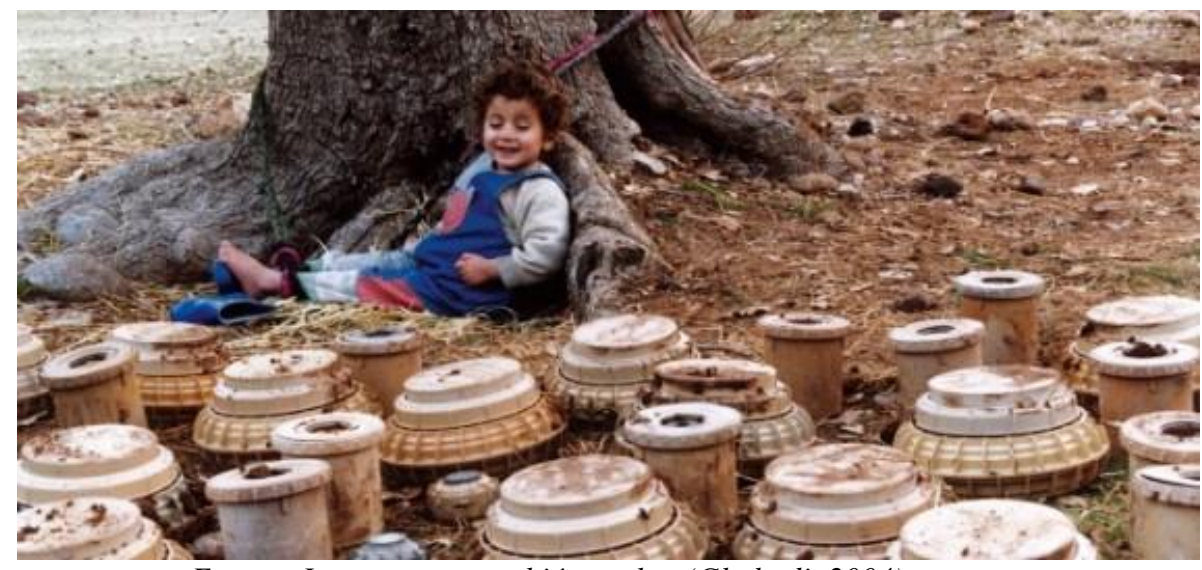

Fuente: Las tortugas también vuelan (Ghobadi, 2004)

Tanto la narración cinematográfica, como el desarrollo de los personajes, los escenarios o los elementos simbólicos, etc., están orientados a la creación del retrato de los niños (García, 2012: 197). Proyectan una imagen positiva porque son niños auténticos, son lo que parecen, son respetuosos, tenaces y fieles en la amistad. Son niños responsables y comprometidos. En la mayoría de las películas ésta es la imagen dominante. Cada niño tiene un objetivo o meta: el pececito de colores de Razieh (El globo blanco, Jafar Panahi, 1995); la senda de vuelta a su domicilio de Mina (El espejo, Panahi, 1997); encontrar los zapatos de Zhara (Niños del Paraíso, Majid Majidi, 1997).

En esa búsqueda para lograr el objetivo está implícita la idea del viaje. Los lugares se convierten en protagonistas de las historias, son espacios cargados de simbolismo: callejuelas, paisajes arbolados, etc. El protagonista está en un viaje perpetuo hacia la búsqueda de la verdad. El camino suele ser zigzagueante, y las calles y las sendas laberínticas, lo que dificulta más el recorrido. El objetivo del viaje es muy concreto, encontrar algo o a alguien. No solo se trata de un viaje exterior, sino también interior. Las imágenes de su soledad en el camino están indicando que la conquista de la paz interior ha de hacerla uno mismo. Para Saeed Talajooy (2012: 247), El espejo es un lugar de reflexión y de reconocimiento, donde un día en la vida de Mina en la ciudad de Teherán crea una nueva forma de realismo. La película muestra la representación de una parte de la vida de 
la niña-personaje, pero se convierte en el viaje a su casa de la niña-real ${ }^{20}$ lo que hace que el espectador se quede, no con imágenes asociadas a la ficción cinematográfica, sino con detalles sobre la vida real de aquellos que no son protagonistas de la película.

Por otra parte, y en relación con el apartado anterior sobre la mujer, su protagonista pone de relieve la cuestión de los derechos de la mujer en la sociedad. Como dice Panahi “El espejo es una película que quiere decir a las nuevas generaciones que seguían actuando con una máscara puesta que se quitaran la máscara y cambiaran la sociedad. Ella ha escuchado una y otra vez que no es bueno para las niñas observar a los encantadores de serpientes, a lo cual ella responde que solo quería ver qué es aquello que no es bueno que vea. Mina lo hace porque tiene la valentía de hacerlo" (Martínez Molina, 2010). También Niños del paraíso nos muestra la postergación de la mujer-niña, en la escuela, en la casa... diferente al papel del hombre-niño.

Hay un trato diferente a los niños y a las niñas por parte de los padres, de los profesores, etc. Zhara asume tareas del hogar a pesar de su corta edad. Vemos a la mujer y la niña servir el té al padre como símbolo de sumisión por parte de la mujer al hombre. En Baran, la chica adolescente se tiene que disfrazar y convertirse en Rhamat ante la amenaza de la autoridad que imponen los hombres, en un universo predominantemente masculino, enfatizando que la situación de las mujeres en la sociedad iraní es mucho más difícil que la de los varones, por el simple hecho de no poder ganarse la vida por ellas mismas.

Para Farshad Zahedi (2012: 138), tanto las leyes de la casa como las reglas del colegio, limitan y obligan al niño a ser obediente. En el ámbito de la escuela, la imagen de la institución, de sus profesores y de los principios educativos son diferentes en cada una de las películas. El ambiente escolar puede ser frío, rutinario, cruel y ajeno los problemas reales de los alumnos (por ejemplo en Niños del paraíso). El profesor puede ser rígido y con poca empatía con sus alumnos. En este ambiente, los alumnos pueden manifestar una sensación de angustia procedente de un sistema educativo intransigente. Pero también

\footnotetext{
${ }^{20}$ Mina se queda mirando a la cámara. Una voz desde detrás de la cámara le dice: "Mina, ¿por qué estás mirando a la cámara? La niña se enoja, y dice que no va a actuar más. Panahi intenta hablar con ella, pero ella se baja del autobús. A medida que el equipo de filmación tratar de averiguar qué hacer, se dan cuenta de su micrófono sigue encendido. Panahi decide seguir grabando su camino a su casa. Así la primera parte funciona como una película y la segunda como un documental, como una película dentro de una película.
} 
podemos encontrar una organización equilibrada, donde haya una alta implicación del alumno y gran empatía por parte del profesor.

Constituyen relatos cinematográficos con connotaciones universales pese a su carácter local. Tras los diálogos o los encuadres subyace y aflora una voz crítica sustentada en la presentación de la verdad, sin sutilezas. Para Francisco García (2012: 187), el niño es "símbolo de la espontaneidad, simplicidad natural, inocencia, retorno al estado embrionario". Según la mitología persa, el niño es la inteligencia intuitiva, no contaminada, por tanto es capaz de ver mejor que los mayores en momentos de dificultad y crisis.

En Baran de Majid Majidi el mito del niño sabio toma como protagonista a una niña adolescente afgana que encuentra la manera de ayudar económicamente a su familia vistiéndose de chico y trabajando como un obrero de la construcción. Por su parte, en El globo blanco destaca la astucia y persistencia con que Razieh consigue que su madre le dé dinero para comprar el pez dorado. Con su carácter fuerte y resuelto, cuestionará los temores de su madre, engendrados en un sistema patriarcal que todavía la sigue identificando únicamente con el rol doméstico y reproductor.

El cine iraní emprende una especie de renovado neorrealismo por medio de relatos, minimalistas y melodramáticos, en los que se hace patente, a través del universo infantil, la preocupación por las desgracias cotidianas relacionadas con la pobreza y la desigualdad social. Por ejemplo, en Niños del paraíso, Alí y su hermana ocultan a sus empobrecidos padres que tienen que compartir unas zapatillas de deporte para asistir a la escuela primaria porque Alí ha perdido los únicos zapatos de su hermana.

Al igual que en el neorrealismo, los cineastas iraníes van a utilizar localizaciones naturales y actores -en este caso niños- no profesionales. También el uso de historias cotidianas, comunes y corrientes, a partir de las que se plantea una preocupación por las condiciones sociales y existenciales de sus personajes, lo que conduce a una radiografía de una sociedad.

En todas estas películas se nos muestra, en general, historias de niños pobres, que tienen enfrentarse e interaccionar en unas circunstancias desfavorables y en un entorno social muy duro contrastándolos, en ocasiones, con niños de clases altas. 


\subsection{La diversidad cultural en el cine iraní}

A pesar de la visión bastante homogénea de Irán que proporcionan los medios occidentales de comunicación, Irán es un país de gran diversidad cultural, con una serie de grupos etno-lingüísticos que incluyes persas, azeríes, árabes, kurdos, baluchis, gilakis, turcomanos, armenios, judíos, asirios, y una variedad de grupos tribales. Además, Irán es una de las zonas más concentradas de inmigrantes y refugiados afganos. ${ }^{21}$ La guerra con Irak de los años ochenta provocó también el desplazamiento de personas, en particular de los kurdos, por las masacres que sufrieron por Saddam Hussein.

Así, al igual que con el tema de la mujer, algunos cineastas se van a interesar en mostrar una visión crítica de las condiciones de vida que sufren algunas de sus minorías marginadas: los kurdos, los árabes y lo refugiados afganos. Ghobadi es uno de ellos y ha intentado plantear una serie de cuestiones relativas a la identidad cultural y diversidad en su país, lo que refleja las contradicciones que surgen entre la política oficial y no oficial con respecto a las minorías étnicas y lingüísticas (Langford, 2012: 259). No olvidemos que, también para abordar este aspecto social, los cineastas iraníes han tenido que trabajar bajo la sombra constante de la censura, por ejemplo a la hora de utilizar otras lenguas como el kurdo.

Ghobadi hace hincapié en la dureza de la frontera como metáfora de la imposibilidad para los kurdos $^{22}$ de unificarse ya sea como una cultura regional o como una nación. De su filmografía nos vamos a centrar en la película Las tortugas también vuelan, que se sitúa en un campo de refugiados de la frontera irano-turca a pocas semanas de la invasión de los Estados Unidos. Uno de los personajes centrales de esta película es un adolescente sin brazos. Este niño es propenso a las visiones (premoniciones). Durante la película se sugiere que tuvo una premonición del atentado contra Halabcheh y la violación de su hermana por un soldado iraquí. Más tarde, de manera similar prevé el inminente

\footnotetext{
${ }^{21}$ A Irán han llegado más de dos millones de afganos a lo largo de décadas de conflicto y sequía de Afganistán (invasión de Rusia en 1979, guerra civil, años del régimen talibán y 11 de septiembre). Gran parte de la joven generación afgana nacida en Irán y no ha viajado nunca a Afganistán. Inicialmente Irán mantenía admitía a los refugiados afganos, pero la situación se ha ido deteriorando en las últimas décadas por el cambio de política de Irán hacia Afganistán (Langford, 2012: 259). Estos refugiados nunca han sido integrados en la sociedad iraní.

${ }^{22}$ Los kurdos de las regiones fronterizas de Irán, Irak y Turquía, mantienen su deseo de establecer un Estado independiente.
} 
ataque de Estados Unidos contra Irak y advierte a los habitantes del campo de refugiados. En su capacidad de prever el futuro, todo lo que ve es conflicto, destrucción y muerte, no hay señales de esperanza para el pueblo kurdo. Otro adolescente llamado Kaak Mahwareh ("Satélite" en kurdo) encabeza un grupo de niños que se dedican a la recuperación de las minas anti-persona en tierras agrícolas. También se dedica a instalar antenas parabólicas a la gente en el pueblo. A pesar del ambiente trágico y amargo de la película, Ghobadi añade ciertas pinceladas de comicidad para rebajar un poco el dramatismo. Por ejemplo, la forma en que los vecinos del pueblo kurdo perciben los programas de televisión y cómo reaccionan ante su contenido. ${ }^{23}$

La película también puede interpretarse como una crítica de Occidente que contempla impasible los horrores y consecuencias de la guerra, que afectan con especial crueldad a los niños. Por eso al final de la película vemos a "Satelite" dar la espalda a los soldados cuando pasan por el campamento, mostrándonos Ghobadi las pocas esperanzas que tiene en los americanos.

Otra película que ilustra el tema de las minorías es Baran del cineasta Majid Majidi, que nos muestra la falta de conciencia -tanto en Irán como en el ámbito internacional- de la difícil situación de los refugiados afganos. Plasma la condición jurídica y social de los afganos que viven y trabajan (muchos de forma ilegal) en Irán. Para Michelle Langford (2012: 274), Majidi incrusta esta denuncia social dentro de una historia de amor, ${ }^{24}$ que le permite moverse en diversos niveles simultáneamente. En un primer nivel, a través de la alegoría nos muestra el amor a través de la utilización de recursos cinematográficos como el viento, la lluvia, el río, el vapor, el fuego, etc. No hay diálogo hablado que esclarezca lo que ocurre entre los personajes. Majidi recurre a las miradas, a los encuentros esquivos, a los objetos, ${ }^{25}$ etc. En otro nivel, pero imbricado en la historia de amor, aparece el contexto de la condición socio-económica de los refugiados afganos en Irán. A través del personaje de Lateef, un sencillo recadero adolescente que trabaja en una obra de construcción,

\footnotetext{
${ }^{23}$ En una de las escenas, uno de los propietarios de la televisión le pide a "Satélite" que bloquee los canales prohibidos para que no los pueda ver nadie. Esto es una referencia explícita a la restricción de los medios de comunicación modernos e independientes y la censura de prensa en Irán (Jahed, 2012: 256).

${ }^{24}$ Lateef descubre detrás de la cortina del cuarto del recadero que Rhamat -que se está peinando su larga cabellera- es en realidad una adolescente afgana (Baran). Lateef se enamora de ella.

${ }^{25}$ El té, como tal, se vuelve significativo: es el mensaje de agradecimiento de Baran hacia Lateef. Este gesto está cargado de significado, y se da de esta manera porque hay que recordar que la chica es afgana (culturalmente no se permite a la mujer la expresión directa de sus sentimientos).
} 
Majidi construye un modelo de entrega desinteresada y modestia. Por su parte, el personaje de Baran es el nexo de unión. Baran con su silencio simboliza a un Afganistán que no puede expresarse. Lateef, consciente de las restricciones sociales y culturales que le impiden unirse a su amada, sacrifica todo para ayudar a Baran y a su familia a regresar a Afganistán, sabiendo que nunca volverá a verla. Mientras Lateef ayuda a estos afganos, dándoles todos sus ahorros -incluso vendiendo su cédula de identidad-, el Estado representado por el inspector del gobierno- busca y expulsa a los afganos ilegales que no pueden trabajar sin un permiso. Este detalle de la película muestra el cambio de la política de Irán hacia los refugiados afganos que, después de 1993, fueron clasificados bajo la etiqueta peyorativa panahandegan (refugiados) y estaban sujetos a restricciones sobre el acceso al trabajo y otros servicios públicos.

Imagen 4. La joven afgana Baran tiene que disfrazarse de chico para poder trabajar

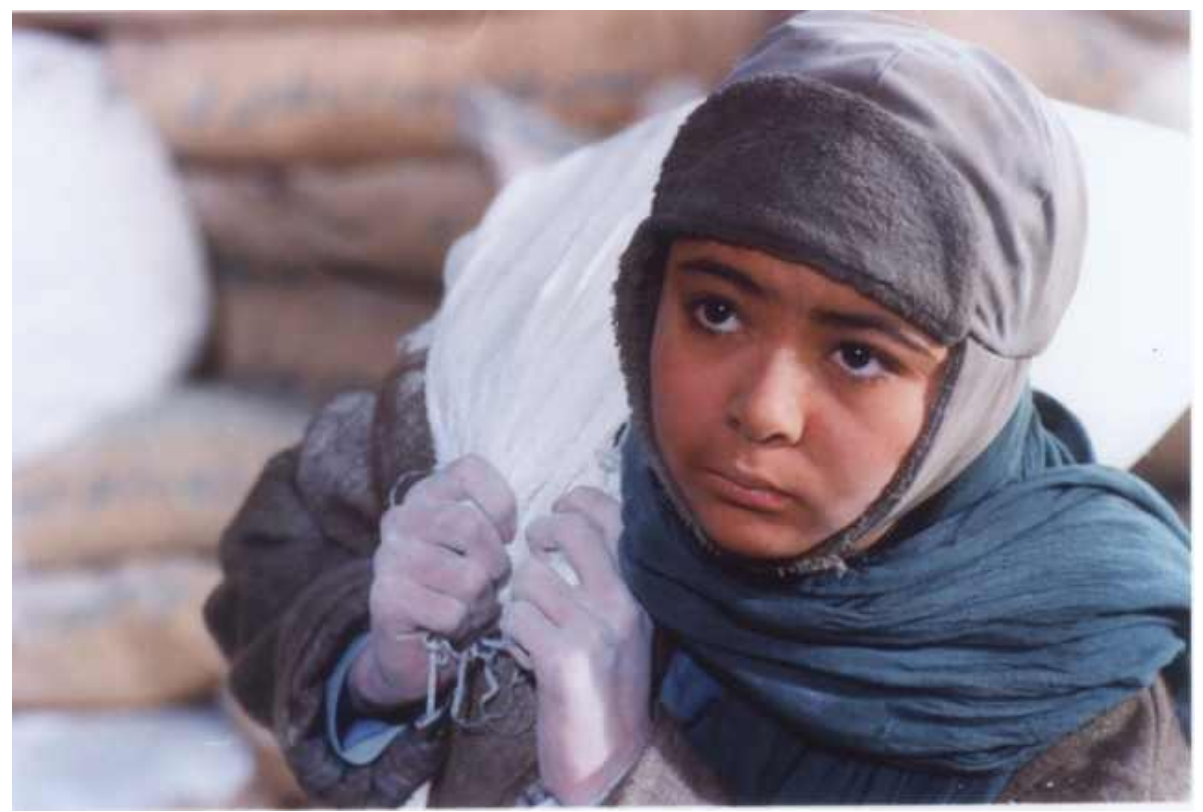

Fuente: Baran (Majidi, 2001)

Majidi entrelaza tres mundos, tres culturas representadas por Irán, Afganistán y Turquía. El microcosmos donde se enlazan estas tres culturas es en un edifico en construcción, donde se juntan inmigrantes afganos y trabajadores turcos. Los trabajadores turcos tienen al menos la ventaja de que nos los expulsen de Irán. Lateef, por su parte, 
representa la inmigración interna, ya que viene de una zona más pobre. A Teherán llegan muchos trabajadores desde diferentes provincias y una vez allí son vistos por la gente como si fueran extranjeros ${ }^{26}$. Debido a la precariedad laboral, los afganos legales o ilegales, aceptan trabajos en los que se les paga menos que a los iraníes. Esto crea fricciones, ya que los iraníes creen que los afganos les están quitando el trabajo. Los obreros iraníes viven y duermen en la misma obra y ocupan habitaciones diferentes en función de su origen étnico. ${ }^{27}$ En la película hay tres habitaciones: la de los lurs, ${ }^{28}$ la de los kurdos y la de los turcos. Los trabajadores afganos no residen en la obra, sino que van y vuelven cada día desde su aldea.

También queda representado el tema de la diversidad cultural en películas como $E l$ globo blanco, por ejemplo, cuando aparece un muchacho afgano que está solo en la calle, mientras el resto de niños están en sus casas preparando la fiesta del Año Nuevo.

Por su parte, en El espejo, según Saeed Talajooy (2012: 248), la variedad étnica de la población se refleja en la banda sonora de la película. O cuando la anciana azarí dice que sus hijos se avergüenzan de su presencia cuando tienen invitados y quieren enviarla a una residencia. Así se aprecia una la multiplicidad de etnias que están presentes en el autobús, reflejo de la rica textura étnica de Irán.

Estas películas nos muestran cómo los cineastas iraníes muestran la diversidad cultural de su país intentando acabar así con el mito de una identidad iraní homogénea (Langford, 2012: 265). La impotencia de las minorías -afganos, kurdos, etc.- se ejemplifica especialmente en personajes errantes, en campos de refugiados y en personas que emprenden arduos viajes tratando de escapar de o volver a sus países de origen. También estas películas dan testimonio y transmiten los efectos devastadores de las guerras.

\footnotetext{
${ }^{26}$ En Niños del paraíso cuando Alí y su padre van a los barrios residenciales de Teherán se pone de manifiesto el contraste de clases sociales -Alí y su padre parecen extranjeros en aquella colonia de compatriotas-.

${ }^{27}$ Baran-Rahmat, Soltan, Najaf y el zapatero son afganos. Lateef, Memar y Faraj son iraníes azeríes. A menudo hablan en turco o mezclan persa y turco. El obrero con quien Lateef se enfrenta por la calidad del té es iraní kurdo. El obrero a quien le cae el yeso en la cabeza y se enfrenta después con Lateef es iraní lur.

${ }^{28}$ De Luristán, una de las provincias occidentales de Irán.
} 


\section{Conclusiones}

Érase un país de espejos, a un lado la vida y al otro su reflejo". Con esta frase se podría resumir la historia del cine iraní. Ángel Fernández-Santos (2002) considera que el cine iraní está constituido por "filmes construidos con recursos de documento, mediante una escrupulosa selección de intérpretes naturales, que en su mayor parte son espejos de sí mismos, lo que da una fortísima verdad a la imagen”. Las películas analizadas pueden verse como representaciones (reflejos) de la realidad y sobre las consecuencias que las injusticias sociales producen, dejando a un lado a los individuos más vulnerables de la sociedad iraní -los niños, adolescentes y mujeres por un lado, y por otro, a los refugiados y distintas minorías. Todas estas películas retratan situaciones de conflicto o de miseria social, ya sea de un modo brutal y despiadado, o de una manera más amable.

Como hemos comprobado, en todas estas películas se exponen una serie de temas prototípicos: amistad, orfandad, pobreza, niños que trabajan, adultos que manipulan a los menores, pérdida de la inocencia. En ellas se muestran las injusticias sociales.

En términos generales, es un cine de ritmo pausado, silencioso, de palabras sencillas, donde los protagonistas nos hacen percibir el drama que les ha tocado vivir. Los personajes son coherentes y verosímiles. Son personajes verdaderos en los que existe una fuerte correlación entre su ser y parecer. Del mismo modo, se tratan temas humanos, primando sobre todo los valores culturales y mirando a sus raíces para reforzar su propia identidad. Paradójicamente, intentando sortear la censura, con las restricciones que ello conlleva, los directores han elevado las cotas de innovación narrativa y cinematográfica.

Por tanto, las películas iraníes saltan del ámbito local para alcanzar un valor universal. Como muy bien dice Francisco García $(2012$, 189) "la ficción puede convertirse en el factor comunicativo de la realidad misma con sus denotaciones propias y su fidelidad descriptiva o aportando elementos que los textos informativos no pueden extraer de la realidad", convirtiéndose estas cintas cinematográficas en una importante fuente documental sobre Irán.

En definitiva, el cine de iraní se nos atoja fascinante. Las obras de los diferentes directores son un paradigma de un cine nacional que muestra la identidad artística y cultural de su país. Nos cautiva la continua aparición de nuevos directores que defienden su idiosincrasia pero sin romper el cordón umbilical que lo une con su tradición cultural. 


\section{BIBLIOGRAFÍA}

- Amirian, Nazanín (2007): “La participación política de la mujer iraní”. En: Política Exterior vol. XXI, nº119, pp: 163-172.

- Atalaya Sociopolítica de Casa Árabe (2009): “Irán dos legados en busca de legado popular”. En: Atalaya Sociopolígica de Casa Árabe, no 6. Junio/Julio, pp. 1-6.

- Elena, Alberto (1995): “La década prodigiosa del cine iraní, 1983-1993”. En: Archivos de la Filmoteca, no 19, pp. 17-27.

. (1999): Los cines periféricos: África, Oriente Medio e India. Barcelona: Paidós. . (2001): “El cine iraní en la era Jatami”. En: El viejo topo, no 148, pp. 58-61.

. (2011): "De Argel a Bombay: paisajes urbanos en el cine contemporáneo". En: Archivos de la Filmoteca, $\mathrm{n}^{\circ}$ 67, pp: 12-22.

- Fernández-Santos, Ángel (2002): Poema de un éxodo, El País, 12 de julio, [en línea] Disponible en: $\quad$ http://elpais.com/diario/2002/07/12/cine/1026424815 850215.html [02/02/2014].

- García, Francisco García (2012): "La imagen del niño en el cine iraní: amistad y responsabilidad”. En: Clara Janneth Santos (coord.): Cine iraní. Madrid: Icono14, pp.163-208.

- Hosseini-Shakib, Fatemeh (2012): "The image of children". En: Parviz Jahed (ed.): Directory of World cinema: Iran, Intellect, pp: 226-233.

- Hotait Salas, Layla (2006): “Cine de autor en Irán, la construcción de una cinematografía nacional". En: Hesperia culturas del Mediterráneo, nº 5 (Ejemplar dedicado a: Irán), pp: 7190.

- Langford, Michelle (2012): “Cultural diversity in Iranian cinema”. En: Parviz Jahed (ed.): Directory of World cinema: Iran, Intellect, pp: 258-266.

- Lloveras, Enric (2014): "Ser mujer en Irán”. En: El Diario, 2 de enero, [en línea] Disponible en: $\quad$ http://www.eldiario.es/desalambre/mujer-Iran_0_209279317.html [31/01/2014].

- Martínez Molina, Julio (2010): Niños en el cine iraní, instancia de representación del porvenir en 5 de septiembre 11 de julio de 2010, [en línea] Disponible en: http://www.5septiembre.cu/index.php?option=com_k2\&view=item\&id=35382:ni\%C3\%B1os- 
en-el-cine-iran\%C3\%AD-instancia-de-representaci\%C3\%B3n-delporvenir\&Itemid=509\&lang=es [20/02/2014].

- Baran (2001) Material extra del DVD. Irán: Divisa, edición 2004.

- Política exterior (2009): “La protesta de las mujeres. Irán después del 12 de junio de 2009”. En: Estudios de Política Exterior, $\mathrm{n}^{\mathrm{o}} 130$ - Julio / Agosto, [en línea] Disponible en: http://www.politicaexterior.com/archives/5401/comment-page-1 [03/02/2014].

- Rajas, Mario (2012): “La construcción de las emociones: Nader y Simin, una separación”. En: Clara Janneth Santos (coord.): Cine iraní. Madrid, Icono14, pp.209-236.

- Santos, Clara Janneth (2012): "El cine iraní y su raigambre socio-cultural”. En: Clara Janneth Santos (coord.): Cine iraní. Madrid: Icono14, pp.37-68.

- Santos, Clara Janneth (coord.) (2012): Cine iraní. Madrid: Icono14.

- Takmil, Nader y Martín, Javier (2003): "Paradojas del cine iraní". En: Le monde diplomatique, $\quad \mathrm{n}^{\mathrm{o}} \quad 51, \quad$ en línea] Disponible en: http://www.insumisos.com/diplo/NODE/2773.HTM [02/02/2014].

- Talajooy, Saeed (2012): “Directors: Jafar Panahi”. En: Parviz Jahed (ed.): Directory of World cinema: Iran, Intellect, pp: 36-41.

- Thoraval, Yves (1995): "El nuevo cine iraní: héroe positivo y tentación estética”. En: Archivos de la Filmoteca, no 19, Todocine (s.a.): "El Circulo", [en línea] Disponible en: http://www.todocine.com/mov/00216145.htm [02/12/2013].

- Tohidi, Nayereh (2009): "Irán: las mujeres en la política”. En: Afkar/Ideas, otoño de 2009, pp. $42-45$.

- Zahedi, Farshad (2010): 40 años de cine iraní. El caso de Dariush Mehryui. Madrid: Fragua.

. (2012): "Los personajes de un particular cine iraní. La renovación del arquetipo cuerpo errante de la literatura persa". En: Clara Janneth Santos (coord.): Cine iraní. Madrid: Icono14, pp. 137-162.

\section{Filmografía}

- Beizâi, Bahrâm (1972): Ragbar (El chaparrón) [película]. Irán: Bahrâm Beizâi. 
- Kiarostami, Abbas (1974): Mosâfer (El viajero) [película]. Irán: Kanoon. . (1987): Jâne-ye Dust Kodjâst? (Dónde está la casa de mi amigo) [película]. Irán: Kanoon, The Institute for the Intellectual Development of Children and Young Adults. . (1997): Ta'm e guilass (El sabor de las cerezas), [Película]. Irán: Abbas Kiarostami Productions

- Farhadi, Asqar (2011): Yodâi-ye Nâder az Simin (Nader y Simin, una separación) [película]. Irán: Asqar Farhadi.

- Ghobadi, Bahman (2004): Lakposhtha hâm parvaz mikonand (Las tortugas también vuelan), [Película]. Irán: Bahman Ghobadi Mij Films.

- Majidi, Majid (1996): Pedar (El padre) [película]. Irán: Center of Documentary and Experimental Cinema.

. (1997): Bacheha-Ye aseman (Niños del paraíso) [película]. Irán: The Institute for the Intellectual Development of Children and Young Adults. . (2001): Baran [película]. Irán: Fouad Nahas.

- Milani, Tahmineh (1998): Do zan (Dos mujeres)[película]. Irán: Arman Film, Arta Film.

- Naderi, Amin (1985): Davandeh (El corredor) [película]. Irán: Studio of the Voice and Portrait of the Islamic Revolution of Iran.

- Panahi, Jafar (1995): Badkonak-e Sefid, (El globo blanco), [Película]. Irán: Ferdos Films. . (1997): Ayneh, (El espejo), [Película]. Irán: Rooz Films. . (2000): Dayereh (El círculo) [película]. Irán: Direction du Développement et de la Coopération (DDC), Département Fédéral des Affaires Etrangères, Foundation Montecinema Verità, Jafar Panahi Film Productions. . (2004): Offside (Fuera de juego) [película]. Irán: Jafar Panahi Film Productions. 